is unfortunate that the growths produced experimentally by Fibiger present just as much difficulty in the elucidation of the exact process as do all other natural growths.

In the past the attempt has often been made to produce cancer by subjecting animals to the irritations associated with cancer in man, but without success except possibly in the case of X-rays. As the writer has pointed out, the irritants vary from one mammal to another, and the knowledge of the irritants to which different species and even their individual organs are liable is of very considerable importance, and will require extensive study. Prof. Fibiger is to be congratulated not only in having isolated such an apparent specific irritant, but also, by carefully imitating the natural process, on having produced cancer experimentally through the mediate intervention of a parasite for the first time.

E. F. BASHFORD.

\section{THE INTERNATIONAL AERO EXHIBITION} AT OLYMPIA.

THE development of the details of flying 1 machines between 1908 and the present time is immediately obvious on a visit to the Aero Exhibition; but, quite apart from the higher standard of workmanship, it is also evident that scientific principles are governing the design of aeroplanes to a greater and greater extent. Almost without exception the designs show evidence of the general desire to keep the resistance of the machines as low as possible and so get increased lifting power and speed. It is not any longer necessary to consider the bare possibility of lift, as the shape of the wings is now so good as to give about $20 \mathrm{lb}$. of lift per horse-power, and engines available for aeroplanes can be obtained of horse-powers up to 160 , weighing less than $3 \mathrm{lb}$. per horse-power; such an engine can then carry, roughly, $\mathrm{I} \frac{1}{2}$ tons, a weight greater than that of any existing aeroplane.

The reduction of resistance does not then arise from necessity, but appears to be directly due to the application of scientific principles. The chief saving in resistance arises from fewer stay-wires and in the covering of the fuselage or tail girder of almost all flying machines, although there are notable exceptions, such as the Maurice Farman biplane exhibited. As compared with the first Wright machine, the stay-wiring of modern machines looks comparatively simple, and in biplanes in particular the struts have been lengthened in the direction of the wind. The strength of the struts is often obtained from a circular steel tube, the desired section for low resistance being obtained from it by the addition of wooden tails and headpieces. The difference of resistance due to shaping the tubes may, on a biplane, increase the carrying capacity of the machine to the extent of another passenger.

The covering of the fuselage to make a streamline body has, however, other effects than that of reducing the resistance. The side surface is considerable, and becomes equivalent to a vertical fin; Prof. Bryan in his book on stability has shown mathematically, what $\mathrm{Mr}$. Lanchester No. $226 \mathrm{I}$, VOL. 90] deduced earlier from a combination of experiment and mathematical analysis, that the position of such fins is of the greatest importance when considering the lateral stability of an aeroplane, and that great care must be taken in the arrangement of such surfaces.

One then looks at the exhibits to find how far aeroplane constructors are designing according to the principles of inherent stability, and how far they leave the control to the skill of the pilot. So far as longitudinal stability is concerned, practically all the machines at the normal flying speed satisfy the mathematical requirements for the stability of small oscillations. The essential features of inherent stability are contained in a series of planes inclined fore and aft, with the angle of incidence from plane to plane decreasing progressively from front to back and in addition having the smaller or elevator planes of sufficient area. Most of the machines, such as the Bleriot, $B E$ 2, \&c., have two surfaces, the main wings and a neutral or nearly neutral tail, whilst the Cody prize machine and the Maurice Farman biplane have each three planes due to the addition of a forward elevator.

Part of the tail plane, and usually the greater part, is fixed to the fuselage of the flying machine, and exercises a control which is independent of the pilot, who is left with the adjustment of the remainder for manœuvring. An exception to this subdivision of the elevator occurs in the Breguet machine, where the whole surface is under the immediate control of the pilot. This latter arrangement has the advantage of a powerful control and the corresponding possible disadvantage of depending entirely on the strength of the pilot for the maintenance of attitude. How much the advantage outweighs the disadvantage is obviously a question to be settled later by the majority of constructors, since it is not yet widely adopted.

With the possible exception of flying at low speeds, it would seem that for longitudinal stability flying machines possess a considerable amount of inherent stability, and only call for serious assistance from the pilot in special circumstances, as when the aëroplane is struck by a gust.

Lateral stability, however, receives far greater variety of treatment, and except that all machines provide large control for the pilot, there is, in the machines exhibited, little evidence of unanimity of method. Leaving out the difficult problem of the spiral dive and considering the machines for lateral stability in linear motion, the points of interest in the machines rest with the positions of the vertical fins or their equivalents.

The most usual combination of fins, which may be seen on the Blériot, Deperdussin, and Bristol machines amongst others, is a dihedral angle between the wings, constituting an equivalent fin above the centre of gravity, and the side of the covered body together with the rudder, the latter making a fin behind the centre of gravity. In a recent lecture before the Aeronautical Society, the superintendent of the Aircraft Factory pointed out that the effect of dihedral angle is dependent to a greater or less extent on the arrangement for 
warping the wings, a freely connected crosswarp tending to eliminate the effect of dihedral angle. If for the time being we neglect the complication introduced by the warping mechanism, the system reduces to one of the cases considered by Messrs. Harper and Bryan, who state that, "for stability, the distance of the tail fin behind the centre of gravity must not be less than a certain inferior limit." The condition is closely connected with the covering of the tail girder, as the covering means that the equivalent fin is brought nearer to the centre of gravity of the machine.

The only representative at the exhibition of another method of obtaining lateral stability is the Handley Page monoplane. In common with other well-known machines, such as the Dunne and Etrich, the Handley Page monoplane has wings of special shape and disposition arranged so as to give righting couples to the machine when rolling or turning occurs. The experimental information available is not yet sufficiently advanced to show that this system of specially shaped wings is either better or worse than the more usual one previously referred to, which depends on wings of a simpler form.

Perhaps the best indication of the position of the subject of lateral stability is to be found in the fact that the whole of the warp and rudder is left to the personality of the pilot. and that both are powerful controls. As the periods of the oscillations are comparatively long, it is quite within the bounds of possibility that a pilot would be able to keep his balance without the aid of inherent stability devices. If, however, the treatment of longitudinal stability is any indication of the trend of construction, then in the near future we may expect considerable attention to be paid to the problems of lateral stability, and that the final solution will not be inconsistent with the principles of stability deduced from mathematical investigations of the stability of small oscillations.

\section{THE SCIENTIFIC WORK OF THE LOCAL GOVERNMENT BOARD.1}

$\mathrm{N}$ the introduction to the report before us $\mathrm{Dr}$. 1 Newsholme surveys the public health of England and Wales during I91 I, and reviews the work of the medical department of the Board for the year ending March 3I, I9I2. The variations in mortality from various diseases since Igor are illustrated by charts, as in the previous report. The percentage increase of population for IgoI-II remains the same $(12.4)$ as in the preceding decade, but this is due to a fall in the death-rate by $3^{\circ} \circ$ per cent., which just counterbalances the decline in the birth-rate. The deaths from scarlet fever continued to decline during I9II, those from diphtheria and enteric fever increased slightly, but those from diarrhøal diseases showed a considerable increase over

1 Forty-first Annual Report of the Local Government Board, xgrr-x2. Supplement containing the Report of the Medical Officer for rorrir. No. $226 \mathrm{I}$, VOL. 90] previous years, due to the abnormally hot season; even so, however, there was less diarrhœa, still less infant mortality, in IgII than in I 899 .

The previously plague-infected district in East Anglia has been kept under observation, and during July-October, I91 $1,{ }^{15,332}$ rats were examined, and twenty-seven farms or other premises were found to harbour plague-infected rodents.

Of the auxiliary scientific investigations carried out for the board, the first is a report on arterial degeneration by Dr. Andrewes. Dr. Newsholme points out in his introductory remarks that while there has been a great reduction in the general death-rate during the past thirty or forty years, this reduction only affects ages up to forty-five years, while higher ages participate in it little or not at all. In fact, for males between fifty-five and seventy-five, the death-rate actually tends to be going up. Inasmuch as one-third of the total deaths for the age period fifty-five to sixty-five is caused by diseases of the heart and bloodvessels, a knowledge of the causation of arterial degeneration is of importance. Dr. Andrewes's report is of a preliminary nature; he considers that the use of tobacco appears at most an adjuvant cause, while the influence of alcohol cannot be satisfactorily demonstrated.

Studies on the frequency of non-lactose fermenting and non-liquefying aërobic bacilli in young children have been continued at Birmingham by Dr. Lewis, and at Liverpool by Dr. Alexander, and Dr. Graham-Smith has investigated the incidence of the same organisms in flies. Prof. Nuttall and Messrs. Strickland and Merriman record observations on the species and number of fleas on British rats.

Prof. Hewlett and Dr. Nankivell have investigated the influence of the Porter-Clark watersoftening process on the bacterial content of water treated by it, and find that considerable purification is effected thereby,

Dr. Blaxall finds that $O^{\prime} I$ per cent. of oil of cloves is a valuable aid in the preparation of glycerinated calf lymph free from microorganisms.

Altogether this volume contains matter of much scientific value and importance.

R. T. H.

\section{THE MOUNTAINS AND THEIR ROOTS. ${ }^{1}$}

(x) $\mathrm{T} T$ would be difficult to conceive a greater I divergence in character and scope between two books, nominally dealing with cognate subjects, than between the two first-named on our list, Prof. Bonney, in his metaphorical use of the word "building," follows popular usage, for how

1 (I) "The Building of the Alps." By Prof. T. G. Bonney, F.R.S. Pp. 384. (London: T. Fisher Unwin, rgr2.) Price 12s. 6d. net.

(2) Survey of India. Professional Paper No. 12: "On-the Origin of the Himalaya Mountains: a Consideration of the Geodetic Evidence." By Colonel S. G. Burrard, F. R.S. P. P. ii +26. (C2lcutta, r9:2.)

(3) Survey of India. Professional Paper No. 13. "Investigation of the Theory of Isostasy in India." By Major H. L. Crosthwait, R.E. Pp. iit+r4. (Delrra Dun, rgra:) 